\title{
Chlorinated Polyethylene. I. Infrared Study
}

\author{
Bienvenu-Magloire Quenum, Philippe Berticat, and Georges Vallet \\ Laboratoire de Chimie Macromoléculaire, Université Claude Bernard \\ 43, Boulevard du 11 Novembre 1918-69621-Villeurbanne, France.
}

(Received June 17, 1974)

\begin{abstract}
A qualitative analysis of the infrared spectra of a series of photochlorinated $\left(20^{\circ} \mathrm{C}\right)$ and thermally $\left(90^{\circ} \mathrm{C}\right)$ chlorinated polyethylenes of various chlorine contents by weight (19\% up to $73 \%$ ) was made. In connection with microstructural high-resolution nuclear-magnetic-resonance studies published in our previous paper, ${ }^{4-6}$ new bands were identified between $500 \mathrm{~cm}^{-1}$ and $2000 \mathrm{~cm}^{-1}$. Changes in the molecular structure of the chlorinated polyethylene samples during the chlorination process were discussed.
\end{abstract}

KEY WORDS Chlorinated Polyethylenes / Poly(vinyl chloride) / Poly(vinylidene chloride) / Band-Assignments / Conformational and Configurational Structures /

The pioneers of infrared study on chlorinated high polymers are Thomson and Torkington; ${ }^{1}$ but the first important infrared study of chlorinated polyethylene (CPE), to which may scientists still refer was published in 1960 by $\mathrm{Nambu}^{2}$ This work was carried out with a series of thermal-chlorinated low-density polyethylene samples of various chlorine contents by weight (20\% up to 68\%).

Since 1970 may microstructural nuclear-magnetic-resonance (NMR) analyses of CPE have been published..$^{3-6}$ NMR is a very efficient tool for this kind of investigation; but infrared analysis is still a fast and routine method which permits conformational and configurational investigations.

This report confirms some band-attributions made by $\mathrm{Nambu}^{2}$ and gives other new ones.

\section{EXPERIMENTAL}

The parent-polymers are a branched low-density polyethylene sample (LDPE), and a linear high-density one (HDPE). Their characteristics, the chlorination conditions, and the techniques of characterization have been published elsewhere $^{4-7}$. A Perkin-Elmer model 421 infrared spectrophotometer was used for the measurements. The films used as experimental samples were obtained by evaporation of the 1,2-dichlorobenzene solution of CPE samples from the sur- face of a heated glass plate $^{1}$. The solvent was removed from the film by heating the glass plate covered with the polymer solution in a furnace at $80^{\circ} \mathrm{C}$, during a period of from $3 \mathrm{hr}$ up to $24 \mathrm{hr}$ depending on the thickness of the films. This treatment, which was necessary in order to have a coherent film, was followed by a $48-\mathrm{hr}$ immersion of the cooled glass plate in methyl alcohol $(\mathrm{MeOH})$ at room temperature. The film was then vacuum dried at $45^{\circ} \mathrm{C}$ for 8 to 15 days depending on its thickness, after immersion in warm $\left(60^{\circ} \mathrm{C}\right) \mathrm{MeOH}$. This warm $\mathrm{MeOH}$ medium was periodically changed. At the end of this treatment $(48 \mathrm{hr})$ the film was again vacuum dried at $45^{\circ} \mathrm{C}$ for 8 to 15 days.

A comparative differential thermal analysis of the films and the powder of the CPE samples ${ }^{8}$ showed that the structure of the chlorinated products is not affected by these various treatments. The spectra of the films are solventband-free.

The infrared spectra of a poly(vinyl chloride) (PVC), a head-to-tail poly(vinylidene chloride) (H-T-PVDC), and poly(vinyl chloride) (CPVC) chlorinated to saturation level $(73 \%)$ were also measured; the samples were pressed into $\mathrm{KBr}$ disks containing $3 \%$ of the product.

\section{RESULTS}

Figure 1 shows the infrared spectrum of the 
initial low-density polyethylene. The spectra of a PVC, a H-T-PVDC, and a $73-\% \mathrm{Cl}_{2} \mathrm{CPVC}$ samples are represented in Figure 2. Different CPE samples spectra (chlorine content: 10,41, 59, and $73-\% \mathrm{Cl}_{2}$ by weight) in the $500-2000-\mathrm{cm}^{-1}$ region

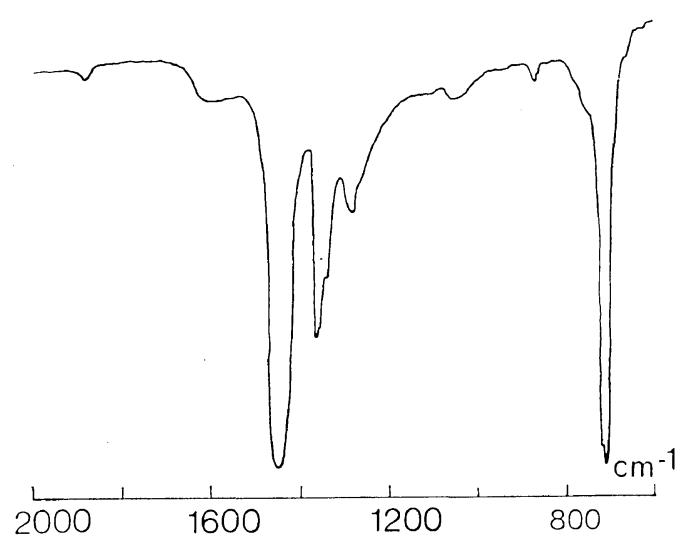

Figure 1. Infrared spectrum $\left(600-2000 \mathrm{~cm}^{-1}\right)$ of a low-density polyethylene (branched polymer).

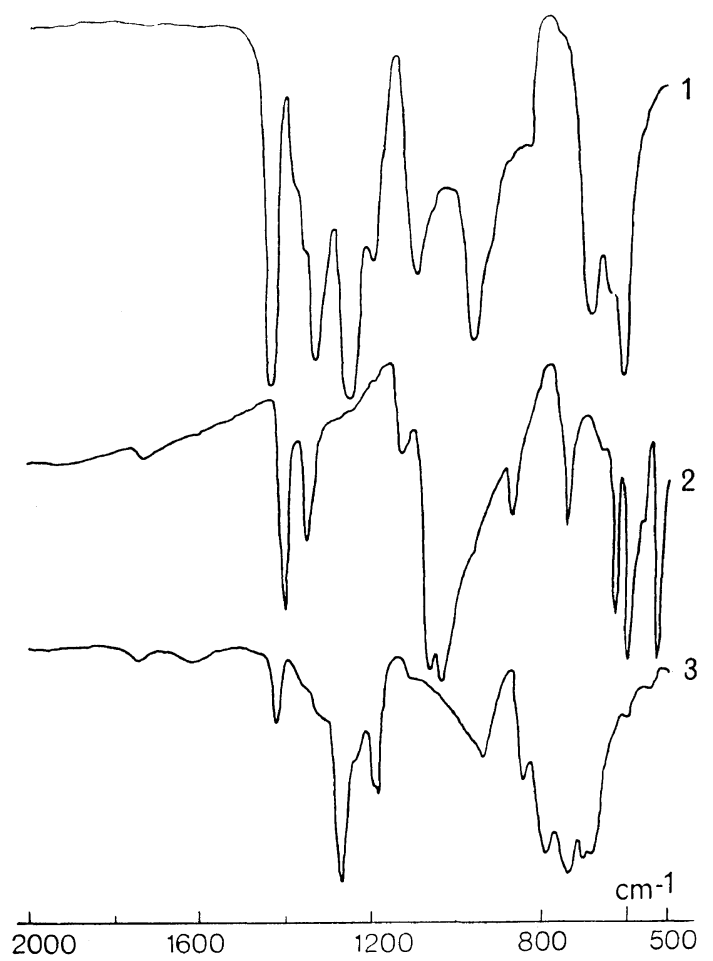

Figure 2. Infrared spectra $\left(500-2000 \mathrm{~cm}^{-1}\right)$ : 1 , poly(vinyl chloride) (PVC); 2, head-to-tail poly(vinylidene chloride) (H-T-PVDC); 3, chlorinated (73\%) poly(vinyl chloride) (CPVC).

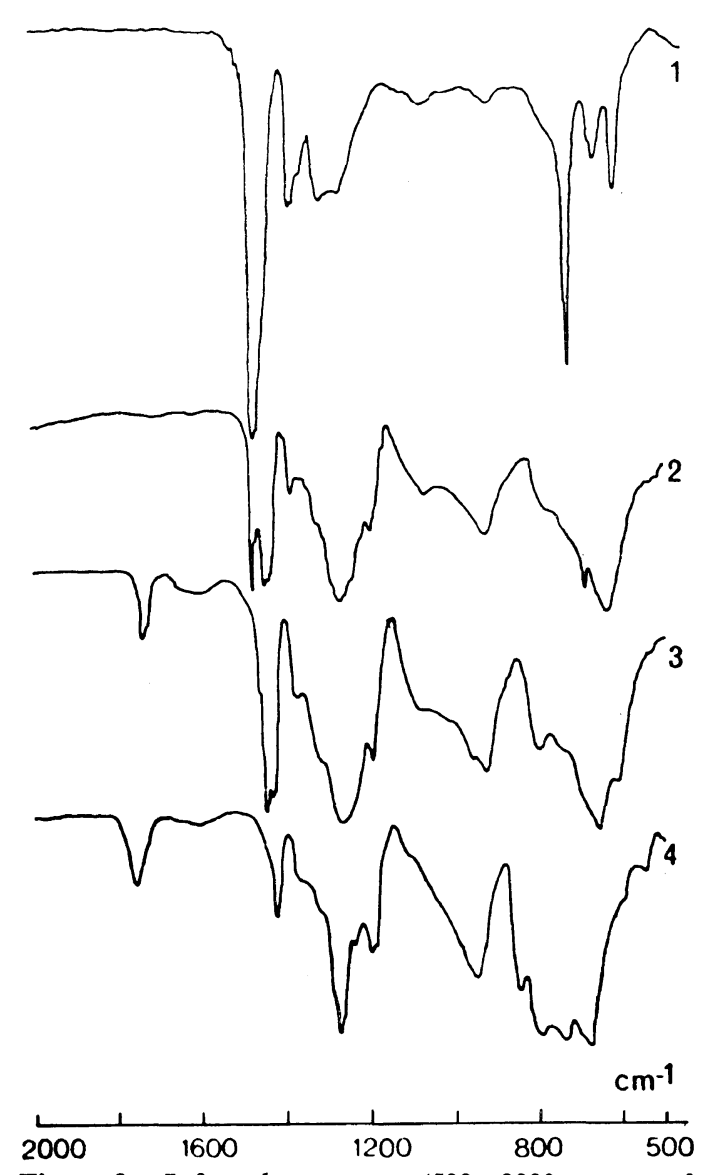

Figure 3. Infrared spectra $\left(500-2000 \mathrm{~cm}^{-1}\right)$ of chlorinated low-density polyethylene (CPE) samples of various chlorine contents by weight: $1,10-\%$ $\mathrm{Cl}_{2}$ (thermal-chlorinated LDPE); $2,41-\% \mathrm{Cl}_{2}$ (thermal-chlorinated LDPE); $3,59-\% \mathrm{Cl}_{2}$ (thermalchlorinated LDPE); 4, 73- $\% \mathrm{Cl}_{2}$ (photochlorinated LDPE).

are shown in Figure 3. Figures 4 and 5 show the $500-800-\mathrm{cm}^{-1}$ region and Figures 8 and 9 the $1100-1500-\mathrm{cm}^{-1}$ region of several CPE; these regions are the most interesting for analysis. In Table II the absorbances of some bands are listed. The arrows near some frequencies indicate the band-shifting as the chlorination proceeds.

\section{DISCUSSION}

The discussion will concern the CPE samples made from the branched low-density polyethylene. Nevertheless, plots of CPE samples made from the linear high-density polyethylene are 
Chlorinated Polyethylene. I.

also shown in Figures 6 and 13 since they are useful in understanding Part $\mathrm{II}^{13}$ of this series.

\section{Assignments of the Infrared Bands}

The 500-800-cm Region. The 610-615- $\mathrm{cm}^{-1}$ band in the PVC spectrum is attributed to the $\mathrm{C}-\mathrm{Cl}$ stretching mode of the $\mathrm{CHCl}$ units in PVC syndiotactic sequences. ${ }^{9}$ Krimm, et al., ${ }^{10-12}$ have called this frequency the $\mathrm{S}_{\mathrm{HH}}$ resonance mode. This band is strong in the spectra of the low-chlorine-content CPE samples and disappears as the photochlorination degree increases beyond $60 \%$ (Table II). At saturation level $\left(73-\% \mathrm{Cl}_{2}\right)$, when the parent polymer is a branched LDPE, the $615-\mathrm{cm}^{-1}$ band appears again if the minimum chlorination time ${ }^{4}$ necessary to obtain $73-\% \mathrm{Cl}_{2}$ is overrun (Figure 13).

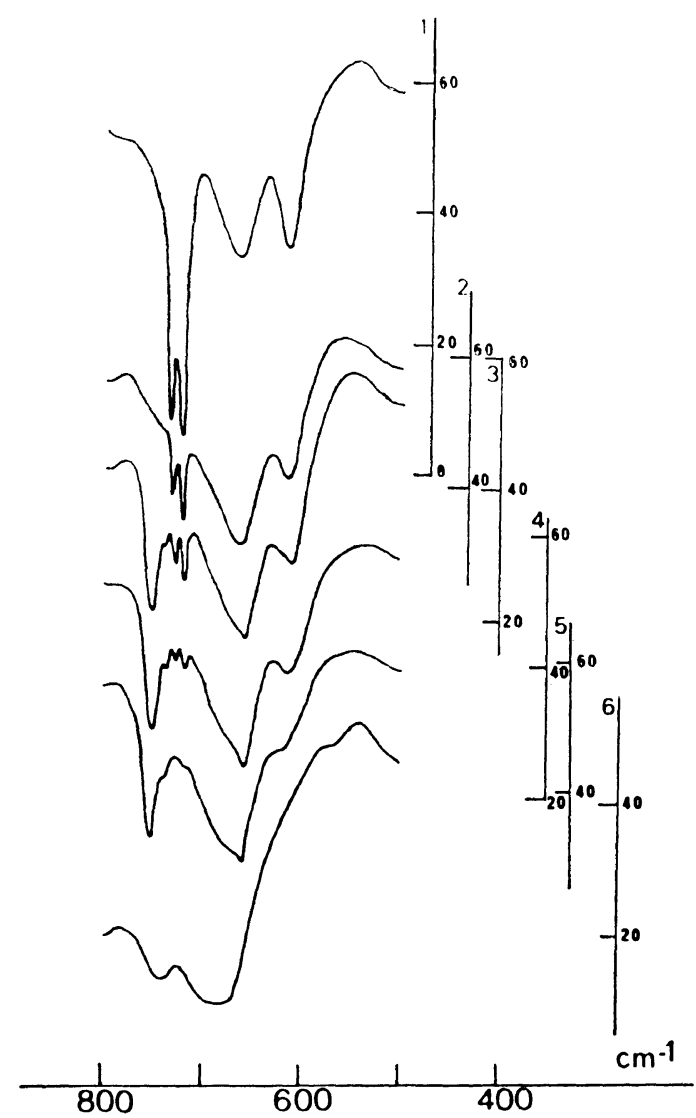

Figure 4. Infrared spectra $\left(500-800 \mathrm{~cm}^{-1}\right)$ of photochlorinated low-density polyethylene samples of various chlorine contents by weight: $1,19.5-\% \mathrm{Cl}_{2}$; 2, 46-\% $\mathrm{Cl}_{2} ; 3,49-\% \mathrm{Cl}_{2} ; 4$, 55-\% $\mathrm{Cl}_{2} ; 5,60.6 \%$ $\mathrm{Cl}_{2} ; 6,68.4-\% \mathrm{Cl}_{2}$.
The PVC spectrum shows a band at $690 \mathrm{~cm}^{-1}$ attributed to the $\mathrm{C}-\mathrm{Cl}$ stretching mode of $\mathrm{CHCl}$ units in PVC isotactic sequences; ${ }^{9}$ this frequency has been termed the $S_{\mathrm{HC}}$ resonance mode by Krimm, et al.. ${ }^{10-12}$ In the CPE samples spectra (Figures 4 and 5) a band appears at $660 \mathrm{~cm}^{-1}$ which shifts to $685 \mathrm{~cm}^{-1}$ and broadens as the chlorination degree proceeds beyond the 55-60-\% interval. In agreement with $\mathrm{Nambu}^{2}$, we assign the $660-\mathrm{cm}^{-1}$ band to the $\mathrm{C}-\mathrm{Cl}$ stretching mode of $\mathrm{CHCl}$ units of vinyl triads surrounded by polyethylene sequences:

$$
\begin{aligned}
& \sim\left(\mathrm{CH}_{2}\right)_{y}-\left(\mathrm{CH}_{2}-\mathrm{CHCl}-\mathrm{CH}_{2}\right)_{m}-\left(\mathrm{CH}_{2}\right)_{x} \cdots \\
& \sim\left(\mathrm{CH}_{2}\right)_{y}-\left(\mathrm{CHCl}-\mathrm{CH}_{2}-\mathrm{CHCl}\right)^{n}-\left(\mathrm{CH}_{2}\right)_{x} \cdots
\end{aligned}
$$

By the 55-60-\% chlorine-content interval the polyethylene sequences are completely changed into vinyl ones. ${ }^{13}$ When the chlorination proceeds beyond $60 \%$ a large number of vinyl

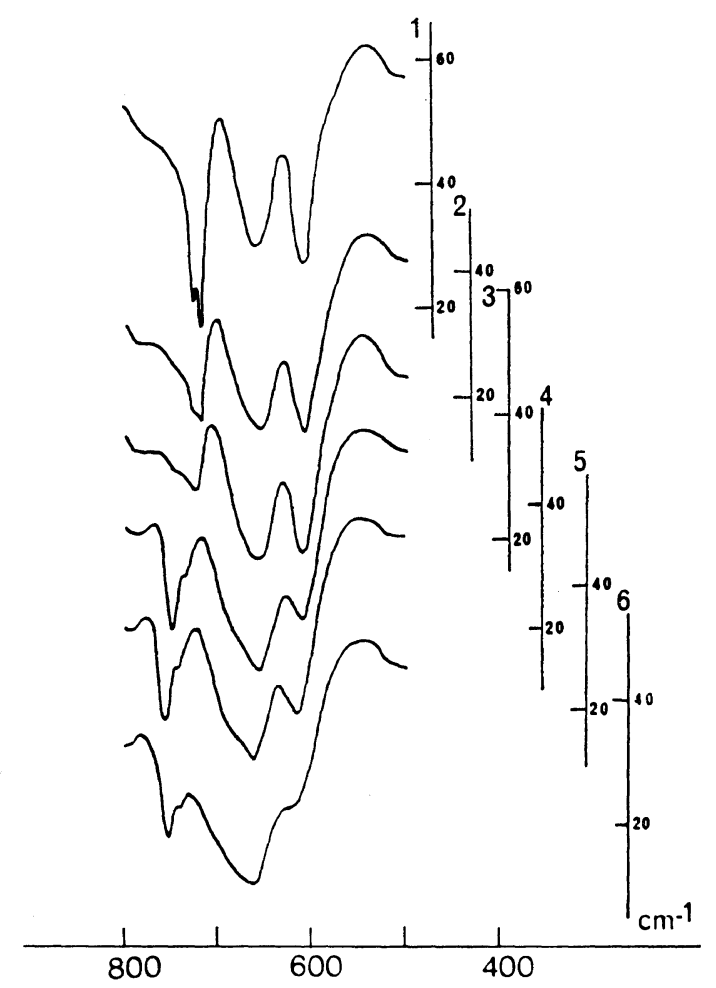

Figure 5. Infrared spectra $\left(500-800 \mathrm{~cm}^{-1}\right)$ of thermal-chlorinated low-density polyethylene samples of various chlorine contents by weight: 1, 24-\% $\mathrm{Cl}_{2} ; 2,33-\% \mathrm{Cl}_{2} ; 3,38-\% \mathrm{Cl}_{2} ; 4,54.5-\% \mathrm{Cl}_{2} ; 5$, $61.5-\% \mathrm{Cl}_{2} ; 6,62.8 \% \mathrm{Cl}_{2}$. 
sequences are changed into $-\mathrm{CH}_{2}-\mathrm{CHCl}-$ $\mathrm{CHCl}-$ and $-\mathrm{CHCl}-\mathrm{CHCl}-\mathrm{CHCl}-$ structures, which can be considered as responsible for the shift of the $660-\mathrm{cm}^{-1}$ band to $685 \mathrm{~cm}^{-1}$; the broadening of this $685-\mathrm{cm}^{-1}$ band is the consequence of the formation of numerous $\mathrm{CHCl}$ units $^{12}$. Adilov and coworkers ${ }^{14}$ assigned the $660-\mathrm{cm}^{-1}$ band to the $\mathrm{C}-\mathrm{Cl}$ stretching mode of the $\mathrm{CCl}_{2}$ units. We think that this is an incorrect attribution because the $-\mathrm{CCl}_{2}-$ units are not so numerous as the $\mathrm{CHCl}$ units; ${ }^{13}$ in addition, the CPE spectra does not show, as the H-T-PVCD spectrum does, any significant band at 520-530 $\mathrm{cm}^{-1}$ which could be attributed to the $\mathrm{C}-\mathrm{Cl}$ stretching mode of the $\mathrm{CCl}_{2}$ units. ${ }^{15}$

The $\mathrm{CH}_{2}$-rocking mode of the initial polymer is found at $720-730 \mathrm{~cm}^{-1} \cdot{ }^{16}$ In the CPE spectra this band disappears progressively as the chlorination proceeds but it is still present until 55-\% chlorine content, which indicates the presence of at least two unchlorinated polyethylene monomeric units $\left(4 \mathrm{CH}_{2}\right)^{1,16}$.

From the 49-55-\% chlorine interval (Figures 4 and 5) a band appears at $740-750 \mathrm{~cm}^{-1}$ which

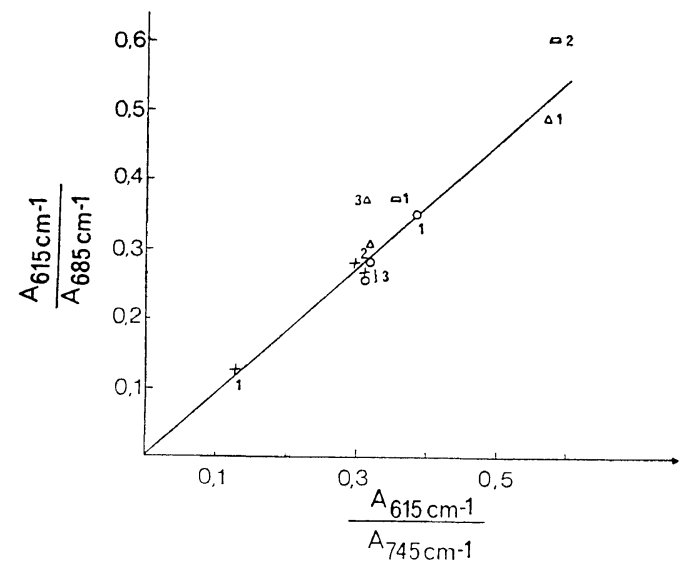

Figure 6. Comparative plots of the $\mathrm{C}-\mathrm{Cl}$ bending mode $\left(740-745 \mathrm{~cm}^{-1}\right)$ and the $\mathrm{C}-\mathrm{Cl}$ stretching mode $\left(685 \mathrm{~cm}^{-1}\right)$ of polyethylene samples chlorinated to saturation level under various conditions. (a) LDPE $(+)$ and HDPE (O) photochlorinated in $\mathrm{CCl}_{4}$ at $20^{\circ} \mathrm{C}$ : (1), $4 \mathrm{hr}$; (2), $6 \mathrm{hr}$; (3), $8 \mathrm{hr}$.

(b) LDPE ( $\triangle$ ) photochlorinated in $\mathrm{CCl}_{4}$ during $4 \mathrm{hr}$ : (1), $0^{\circ} \mathrm{C}$; (2), $40^{\circ} \mathrm{C}$; (3), $60^{\circ} \mathrm{C}$.

(c) LDPE (口) photochlorinated in 1,1,2,2-tetrachloroethane (TCE) during $4 \mathrm{hr}$ : (1), $100^{\circ} \mathrm{C}$; (2), $130^{\circ} \mathrm{C}$. could be assigned to the $\mathrm{C}-\mathrm{Cl}$ bending mode of the $-\mathrm{CHCl}$ - units in structures such a $-\mathrm{CH}_{2}-\mathrm{CHCl}-\mathrm{CHCl}-$ or $-\mathrm{CHCl}-\mathrm{CHCl}-$ $\mathrm{CHCl}-$. This assignment is consistent with the following considerations:

This band becomes a strong one when the $-\mathrm{CH}_{2}-\mathrm{CHCl}-\mathrm{CHCl}-$ and $-\mathrm{CHCl}-\mathrm{CHCl}-$ $\mathrm{CHCl}$ - structures appear in large numbers, as proved by NMR studies. ${ }^{6,13}$

The plot of $A_{615} / A_{685}$ against $A_{615} / A_{745}$ (for absorbance) (Figure 6) for CPE samples at the saturation level $(73 \%)^{4}$ is a straight line, which indicates that the $745-\mathrm{cm}^{-1}$ and $685-\mathrm{cm}^{-1}$ bands deal with the same structures.

We assign the weak band which appears at $785 \mathrm{~cm}^{-1}$ and shifts to $800 \mathrm{~cm}^{-1}$ when the chlorination proceeds to a vibrational mode of $\mathrm{CHCl}$. Figure 7 shows that this band and the 1195$1200-\mathrm{cm}^{-1}$ band have the same variation. A band $\left(1195-1200 \mathrm{~cm}^{-1}\right)$ which is not present in
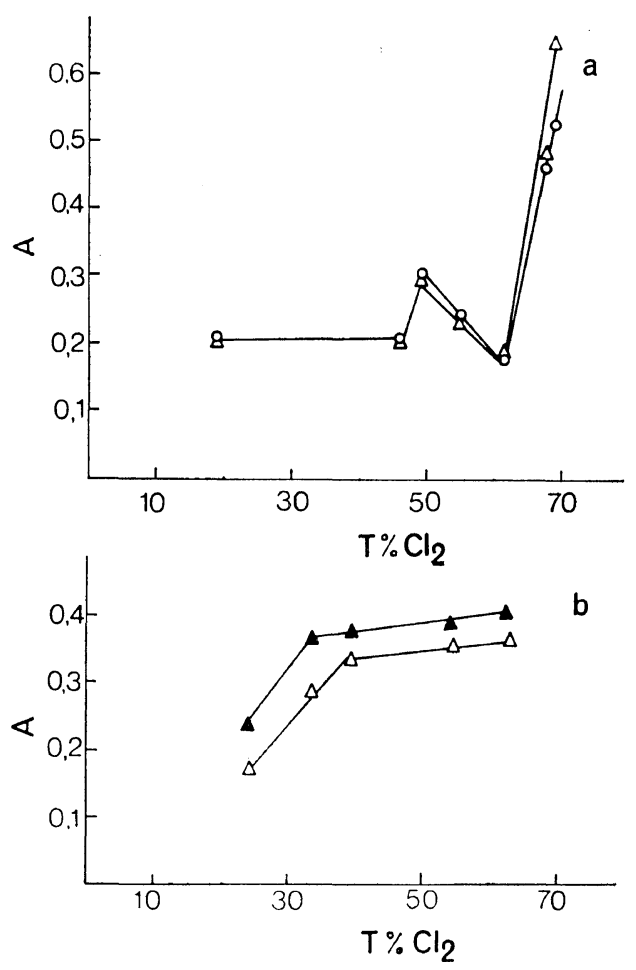

Figure 7. Comparative plots of the $785-\mathrm{cm}^{-1}$ band and the $1200-\mathrm{cm}^{-1}$ band: (a), photochlorinated polyethylene samples $\left(\triangle 785 \mathrm{~cm}^{-1}, \bigcirc 1200 \mathrm{~cm}^{-1}\right)$; (b), thermal-chlorinated polyethlene samples ( $\triangle 785$ $\mathrm{cm}^{-1}, \triangle 1200 \mathrm{~cm}^{-}$). 
Chlorinated Polyethylene. I.

Table I. The infrared bands' assignment

\begin{tabular}{|c|c|c|c|c|}
\hline$\underset{\mathrm{cm}^{-1}}{\text { Frequency, }}$ & $\begin{array}{l}\text { Resonance } \\
\text { mode }\end{array}$ & $\begin{array}{l}\text { Atoms } \\
\text { concerned }\end{array}$ & $\begin{array}{l}\text { Units } \\
\text { concerned }\end{array}$ & Structures concerned in the CPE chains \\
\hline $610-615$ & Stretching & $\mathrm{C}-\mathrm{Cl}$ & $-\mathrm{CHCl}-$ & PVC Syndiotactic sequences \\
\hline 690 & Stretching & $\mathrm{C}-\mathrm{Cl}$ & $-\mathrm{CHCl}-$ & PVC Isotactic sequences \\
\hline 685 & Stretching & $\mathrm{C}-\mathrm{Cl}$ & $-\mathrm{CHCl}-$ & $\begin{array}{l}\left(\mathrm{CH}_{2}-\mathrm{CHCl}-\mathrm{CHCl}\right)(\mathrm{CHCl}-\mathrm{CHCl}-\mathrm{CHCl}) \\
\text { and } \mathrm{PVC} \text { isotactic sequences }\end{array}$ \\
\hline $720-730$ & Rocking & & $-\mathrm{CH}_{2}-$ & $\left(\mathrm{CH}_{2}\right)_{n} \quad(n \geq 4)$ \\
\hline $740-750$ & Bending & $\mathrm{C}-\mathrm{Cl}$ & $-\mathrm{CHCl}-$ & $\left(\mathrm{CH}_{2}-\mathrm{CHCl}-\mathrm{CHCl}\right) \quad(\mathrm{CHCl}-\mathrm{CHCl}-\mathrm{CHCl})$ \\
\hline $785-800$ & Bending & & $-\mathrm{CHCl}-$ & $\left(\mathrm{CH}_{2}-\mathrm{CHCl}-\mathrm{CHCl}\right) \quad(\mathrm{CHCl}-\mathrm{CHCl}-\mathrm{CHCl})$ \\
\hline $825-850$ & Rocking & & $-\mathrm{CH}_{2}-$ & $-\mathrm{CHCl}-\mathrm{CH}_{2}-\mathrm{CCl}_{2}-$ \\
\hline $1195-1200$ & Deformation & & $-\mathrm{CHCl}-$ & $\begin{array}{l}(\mathrm{CHCl}-\mathrm{CHCl}-\mathrm{CHCl}) \quad\left(\mathrm{CH}_{2}-\mathrm{CHCl}-\mathrm{CHCl}\right) \\
\text { and } \mathrm{PVC} \text { sequences }\end{array}$ \\
\hline $1375-1380$ & Deformation & & $-\mathrm{CH}_{3}-$ & $-\mathrm{CH}_{2}-\underset{\mid}{\mathrm{C}} \mathrm{H}-\mathrm{CH}_{2}-$ and $-\mathrm{CH}_{2}-\underset{\|}{\mathrm{C}}-\mathrm{O}-\mathrm{CH}_{3}{ }^{13}$ \\
\hline $1440-1430 \rightarrow 1428$ & Bending & & $-\mathrm{CH}_{2}-$ & PVC Syndiotactic sequences \\
\hline $1450-1445 \rightarrow 1434$ & Bending & & $-\mathrm{CH}_{2}-$ & PVC Isotactic sequences \\
\hline $\begin{array}{l}1470 \\
1465 \\
1460\end{array}$ & $\begin{array}{l}\text { Bending } \\
\text { Bending } \\
\text { Bending }\end{array}$ & & $\begin{array}{l}-\mathrm{CH}_{2}- \\
-\mathrm{CH}_{2}- \\
-\mathrm{CH}_{2}-\end{array}$ & $\begin{array}{l}-\mathrm{CHCl}-\left(\mathrm{CH}_{2}\right)_{x}-\mathrm{CHCl}- \\
-\mathrm{CHCl}-\left(\mathrm{CH}_{2}\right)_{y}-\mathrm{CHCl}-\text { with } x>y>z \\
-\mathrm{CHCl}-\left(\mathrm{CH}_{2}\right)_{z}-\mathrm{CHCl}\end{array}$ \\
\hline
\end{tabular}

Table II. Absorbances of some infrared bands tabulated in Table I

\begin{tabular}{lllllllllll}
\hline $\mathrm{cm}^{-1}$ & $\mathrm{~cm}^{-1}$ & $\mathrm{~cm}^{-1}$ & $\mathrm{~cm}^{-1}$ & $\mathrm{~cm}^{-1}$ & $\mathrm{~cm}^{-1}$ & \multicolumn{2}{c}{$\mathrm{cm}^{-1}$} & \multicolumn{3}{c}{$\mathrm{cm}^{-1}$} \\
\hline 1470 & 1450 & 1440 & & & & & 615 & 720 & 615 & 785 \\
$1465 \downarrow^{2}$ & $1445 \downarrow$ & $1430 \downarrow$ & 1195 & 615 & 660 & $\frac{615}{660}$ & 725 & $\frac{750}{750}$ & 800 & $\mathrm{Cl}_{2}, \%$ \\
4460 & 1434 & 1428 & 1200 & & $685 \downarrow$ & & 750 & & \\
\hline
\end{tabular}

Thermal chlorination of the branched polyethylene (LDPE) at $90^{\circ} \mathrm{C}$ in 1,1,2,2-tetrachloroethane (TCE)

\begin{tabular}{lllllllllll}
\hline 1.327 & 0.783 & 0.674 & 0.189 & 0.497 & 0.452 & 1.1 & 0.699 & 0.715 & 0.235 & 24 \\
1.092 & 0.930 & 0.812 & 0.288 & 0.671 & 0.671 & 1 & 0.935 & 1.595 & 0.369 & 33 \\
0.989 & 0.892 & 0.778 & 0.335 & 0.636 & 0.662 & 0.960 & 0.444 & 0.430 & 1.360 & 38 \\
0.662 & 0.832 & 0.739 & 0.338 & 0.596 & 0.815 & 0.804 & 0.474 & 1.260 & 0.379 & 54.5 \\
0.753 & 0.893 & 0.783 & 0.361 & 0.639 & 0.850 & 0.753 & 0.498 & 1.280 & 0.417 & 61.5 \\
0.411 & 0.712 & 0.672 & 0.418 & 0.551 & 0.625 & 0.625 & 0.540 & 1.020 & 0.384 & 62.8 \\
\hline
\end{tabular}

Photochlorination of the branched polyethylene (LDPE) at $20^{\circ} \mathrm{C}$ in 1,1,2,2-tetrachloroethane (TCE)

\begin{tabular}{lllllllllll}
\hline 1.425 & 0.757 & 0.580 & 0.204 & 0.358 & 0.384 & 0.935 & 1.240 & 0.290 & 0.195 & 19.5 \\
0.763 & 0.448 & 0.359 & 0.183 & 0.328 & 0.448 & 0.730 & 0.395 & 0.827 & 0.191 & 46 \\
1.697 & 0.676 & 0.629 & 0.280 & 0.463 & 0.689 & 0.675 & 0.494 & 0.938 & 0.285 & 49 \\
0.790 & 0.441 & 0.427 & 0.216 & 0.348 & 0.541 & 0.660 & 0.337 & 1.030 & 0.219 & 55 \\
0.454 & 0.316 & 0.276 & 0.198 & 0.272 & 0.468 & 0.582 & 0.311 & 0.875 & 0.183 & 60.6 \\
0 & 0.577 & 0.287 & 0.462 & 0 & 0.898 & 0 & 0.696 & 0 & 0.484 & 67.5 \\
0 & 0.240 & 0.541 & 0.524 & 0 & 0.962 & 0 & 0.825 & 0 & 0.638 & 68.4 \\
0 & 0.237 & 0.431 & 0.500 & 0 & 0.980 & 0 & 0.800 & 0 & 0.645 & $73^{\mathrm{c}}$ \\
\hline
\end{tabular}

a The arrows near some frequencies indicate the band-shifting when the chlorination procedures.

b Chlorine content by weight.

c After $4 \mathrm{hr}$ of photochlorination. 
the initial polyethylene spectrum is found in the PVC one; Fredriksen and Crowo ${ }^{17}$ attributed it to the $-\mathrm{CH}$ - deformation mode of $\mathrm{CHCl}$.

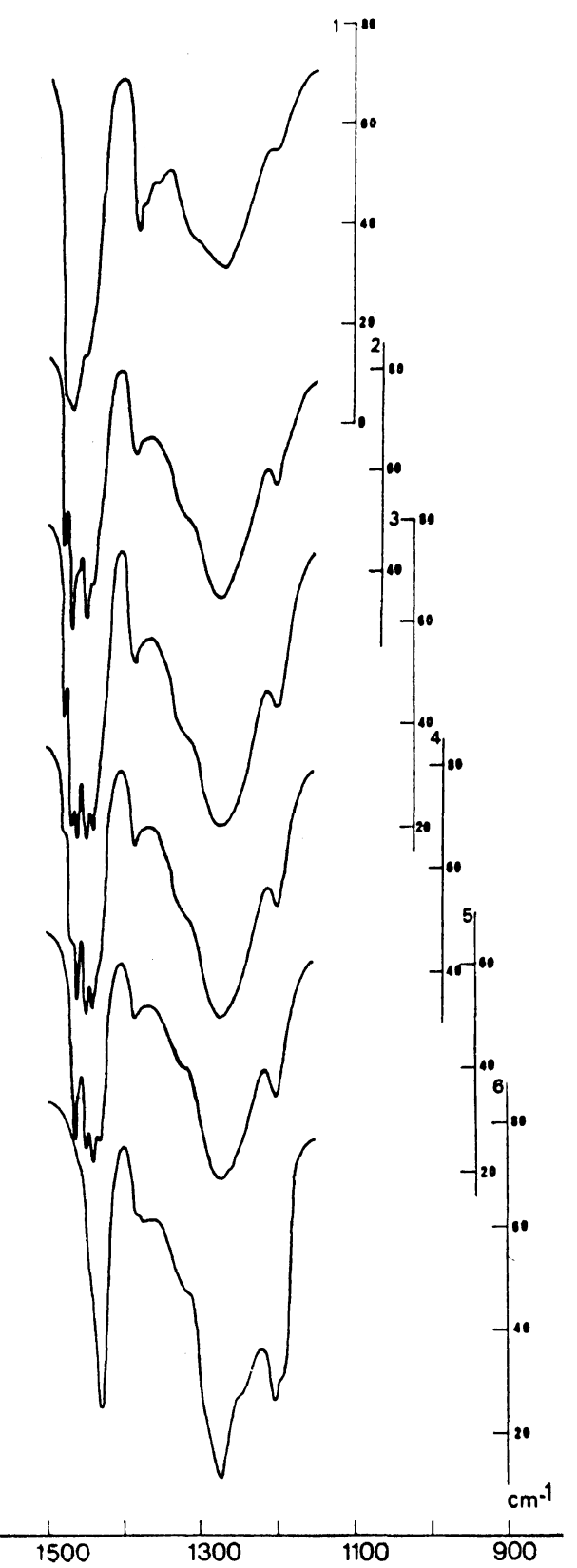

Figure 8. Infrared spectra $\left(1100-1500 \mathrm{~cm}^{-1}\right)$ of photochlorinated low-density polyethylene samples of various chlorine contents by weight: 1, 19.5-\% $\mathrm{Cl}_{2} ; 2,46-\% \mathrm{Cl}_{2} ; 3,49-\% \mathrm{Cl}_{2} ; 4,55-\% \mathrm{Cl}_{2} ; 5$, 60.6-\% $\mathrm{Cl}_{2} ; 6,68.4-\% \mathrm{Cl}_{2}$.
The 800-1000- $\mathrm{cm}^{-1}$ Region. In the spectrum of the $63-\%$ photochlorinated CPE sample (Figure 4) a band appears at $825 \mathrm{~cm}^{-1}$ and shifts to 850

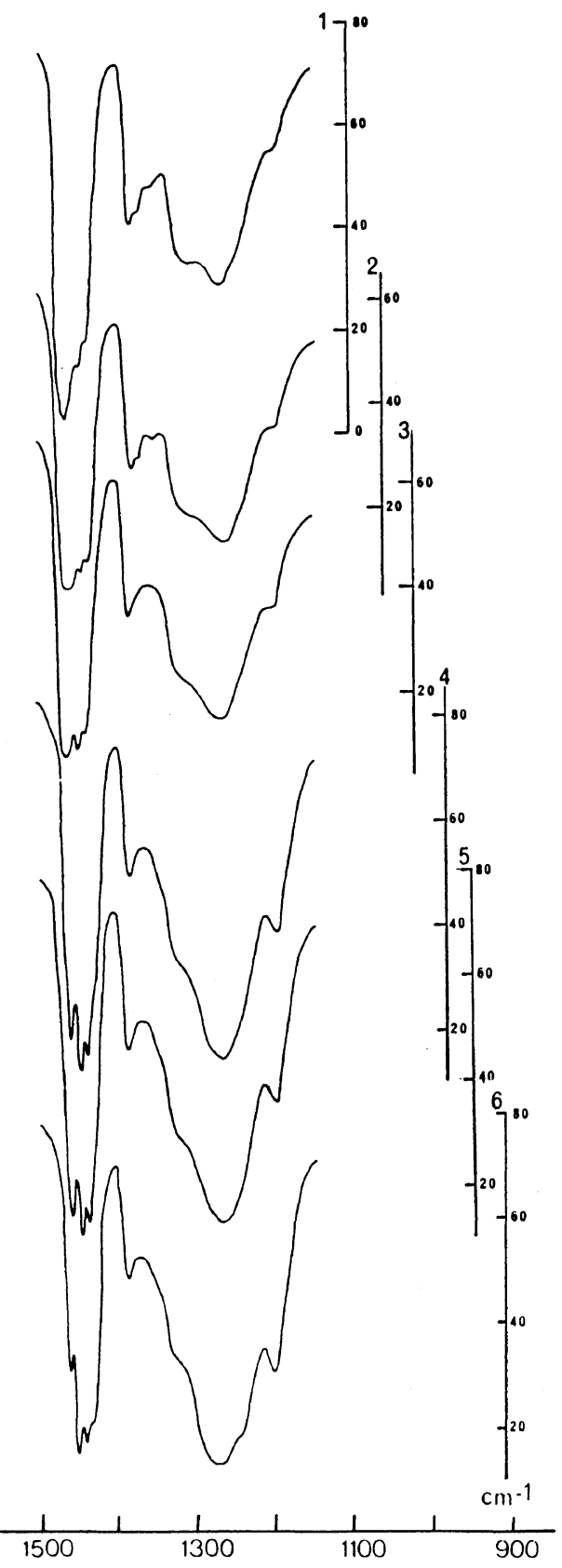

Figure 9. Infrared spectra $\left(1100-1500 \mathrm{~cm}^{-1}\right)$ of thermal chlorinated low density polyethylene samples of various chlorine contents by weight: $1,24-\% \mathrm{Cl}_{2} ; 2,33-\% \mathrm{Cl}_{2} ; 3,38-\% \mathrm{Cl}_{2} ; 4,54.5 \%$ $\mathrm{Cl}_{2} ; 5,61.5-\% \mathrm{Cl}_{2} ; 6,62.8 \% \mathrm{Cl}_{2}$. 
$\mathrm{cm}^{-1}$ for the saturated (73\%) CPE sample (Figure $3)$. We assign it to the $-\mathrm{CH}_{2}-$ rocking mode of the $-\mathrm{CHCl}-\mathrm{CH}_{2}-\mathrm{CCl}_{2}-$ structure. NMR analyses ${ }^{6,13}$ show that these structures are numerous in the $60-73-\%$ chlorine interval. A similar band has been attributed by Murayama and Amagi $^{18}$ to the $-\mathrm{CH}_{2}-$ rocking mode of headto-head poly(vinylidene chloride) (H-H-PVCD).

The 1100-1500- $\mathrm{cm}^{-1}$ Region. In agreement with $\mathrm{Nambu}^{2}$ we assign the band which appears at $1470 \mathrm{~cm}^{-1}$ or $1465 \mathrm{~cm}^{-1}$ or $1460 \mathrm{~cm}^{-1}$ in the CPE samples spectra to polyethylene sequences of various length. The absorbance values listed in Table II show that the polyethylene sequences disappear faster in the photochlorination process than in the thermal one.

Satoh and Enomoto ${ }^{19}$ made spectroscopic studies of vinylidene chlorine-vinyl chloride copolymers and attributed the $1448-\mathrm{cm}^{-1}$ band to the $-\mathrm{CH}_{2}-$ bending mode of head-to-head PVC and the $1445-\mathrm{cm}^{-1}$ band to the $\mathrm{CH}_{2}$ bending mode of H-H-PVCD. Such bands are present at $1450-1445 \mathrm{~cm}^{-1}$ and $1440-1430 \mathrm{~cm}^{-1}$ in the CPE samples spectra and shift respectively to $1434 \mathrm{~cm}^{-1}$ and $1428 \mathrm{~cm}^{-1}$ when the PVC sequences lengthen in the CPE chains. ${ }^{6,13}$ By comparison with $\mathrm{PVC}^{9-12}$ we assign the $1440-1430 \rightarrow 1428$ $\mathrm{cm}^{-1}$ band and the $1450-1455 \rightarrow 1434-\mathrm{cm}^{-1}$ band respectively to the vinyl syndiotactic and isotactic structures present in the CPE chains.

It was impossible to identify and band at 1422 $\mathrm{cm}^{-1}$ and $1405-1410 \mathrm{~cm}^{-1}$ which could be assigned respectively to the $\mathrm{CH}_{2}$ bending mode of $-\mathrm{CHCl}-\mathrm{CH}_{2}-\mathrm{CCl}_{2}-$ and $-\mathrm{CCl}_{2}-\mathrm{CH}_{2}-$ $\mathrm{CCl}_{2}-$ structures. ${ }^{19}$

The $\mathrm{CH}_{3}$ deformation mode of the initial polyethylene is found at about $1375-1380 \mathrm{~cm}^{-1}$. $^{3,16}$ This band is still present in the spectra of all the CPE samples. $\mathrm{Nambu}^{2}$ drew the conclusion that methyl groups are still found in CPE; but did not give any precise statement about the origin of these methyl groups. Dynamic mechanical properties of CPE samples ${ }^{20}$ show that the temperature of the $\beta$-relaxation of the initial polyethylene, related to $-\mathrm{CH}_{2}-\mathrm{CH}-\mathrm{CH}_{2}-$ $\mathrm{R}$

structure by Robinson, ${ }^{21}$ stands almost at the same position for thermally chlorinated (up to 40-\% chlorine content) CPE samples made from a branched polyethylene. Therefore one can draw the conclusion that with thermal chlorination, during the first chlorination-step, some branchings of the parent-polymer and particularly methyl groups remained unchlorinated. But in the case of photochlorinated and thermal CPE samples of high chlorine content by weight, there is a connection between the recovering method of the CPE samples from the chlorination medium and the $1375-1380-\mathrm{cm}^{-1}$ band. Indeed, after the predeterminated reaction period the reaction mixture is poured into a large volume of $\mathrm{MeOH}$ to precipitate the chlorinated product (1 volume of reaction mixture against 3 volumes of $\mathrm{MeOH}$ ); the acylchloride structures present in the CPE chains react with $\mathrm{MeOH}$ produce acetate structures ${ }^{13}$ whose methyl groups give the $1375-1380-\mathrm{cm}^{-1}$ band and whose carbonyl groups are responsible for the 1740-1760$\mathrm{cm}^{-1}$ band.

Spectra Nos. 1 and 2 in Figure 10 compare a 73-\% $\mathrm{Cl}_{2}$ (CPE sample) degree of polymerization $\overline{\mathrm{DP}}_{n}=627$ ) with its fraction of the lowest numberaverage molecular weight $\left(\overline{\mathrm{DP}}_{n}=67\right) \cdot{ }^{13}$ Spectrum No. 2 shows that the $1375-1380-\mathrm{cm}^{-1}$ band and the $1740-1760-\mathrm{cm}^{-1}$ band are stronger than the corresponding ones in the spectrum No. 1, which indicates that the carbonyl groups are localized

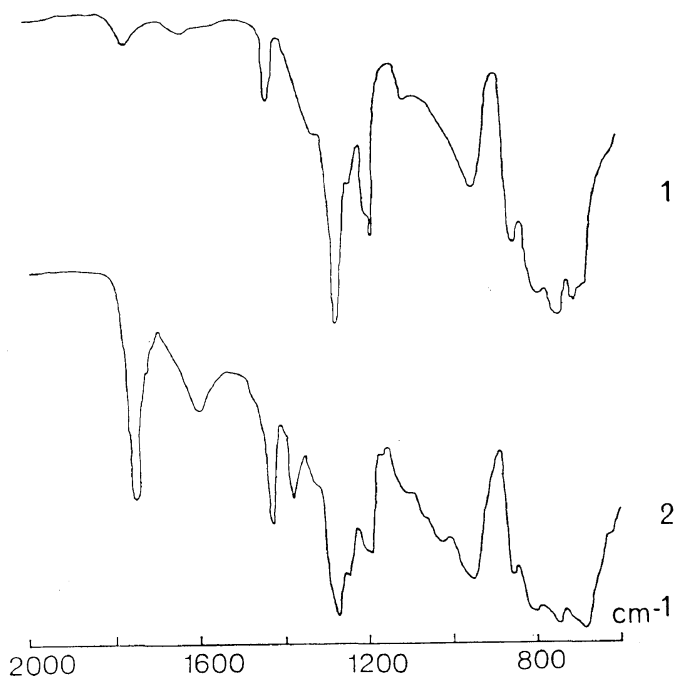

Figure 10. Infrared spectra $\left(600-2000 \mathrm{~cm}^{-1}\right): 1$, chlorinated low-density polyethylene $\left(73-\% \quad \mathrm{Cl}_{2}\right)$ $\overline{\mathrm{DP}}_{n}, 627 ; 2$, chlorinated low-density polyethylene (69-\% $\left.\mathrm{Cl}_{2}\right) \overline{\mathrm{DP}}_{n}, 67$. 
at the ends of the chlorinated chains. The strong $1600-1640-\mathrm{cm}^{-1}$ band which appears in spectrum No. 2 of Figure 10 indicates the presence of some $\mathrm{C}=\mathrm{C}$ bonds at the end of the CPE chains.

\section{Configurational and Conformational Changes in $C P E$}

Shimanouchi and Tasumi ${ }^{22}$ demonstrated that the PVC syndiotactic sequences are energetically stable when the $\mathrm{C}-\mathrm{C}$-bond internal rotation arrangement are trans $(T)$. This arrangement avoids close contact between 2 successive chlorine atoms. But the PVC isotactic sequences are energetically stable if 2 successive $\mathrm{C}-\mathrm{C}$ bonds (2 successive monomeric units) are $T$ and gauche $(G)$ or $G$ and $T$. The conformational structures linked to each kind of PVC configurational structure are represented in Figures 11a and $b$.

The $T T$ syndiotactic conformation has been related to the $615-\mathrm{cm}^{-1}$ band or to the $\mathrm{S}_{\mathrm{HH}}$ reronance mode and the $T G$ or $G T$ isotactic conformation to $690-\mathrm{cm}^{-1}$ band or to the $S_{\mathrm{HC}}$ resonance mode by some authors ${ }^{11,12}$ who stated that the ratio $A_{615} / A_{690}$ can be used to calculate the

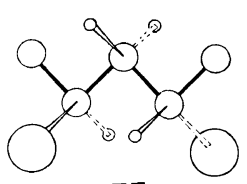

T T

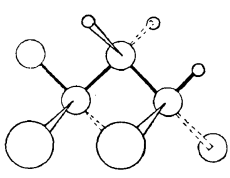

TG'

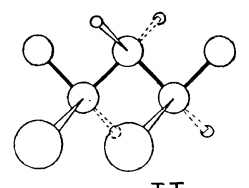

T T

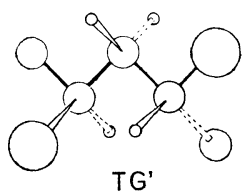

TG'
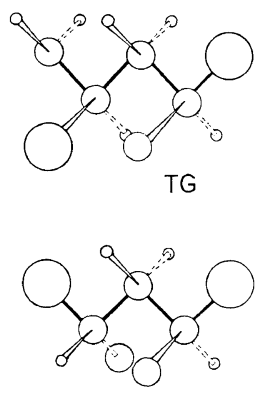

G
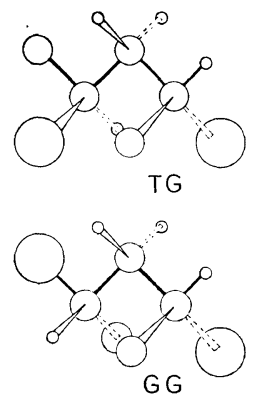

G G
Figure 11. (a) Conformations of a PVC syndiotactic diad.

(b) Conformations of a PVC isotactic diad.

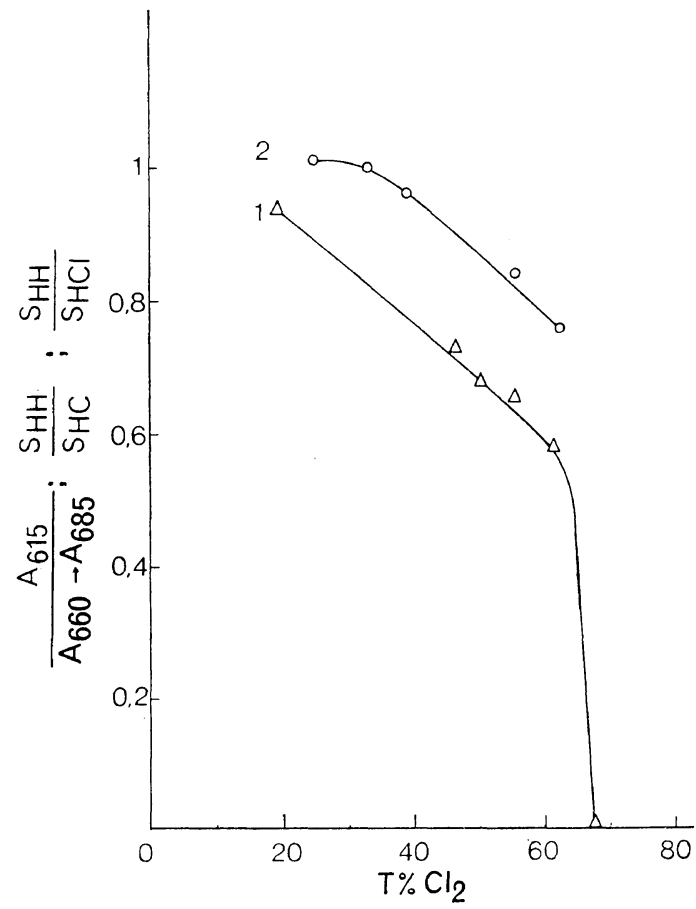

Figure 12. Conformational changes in the polymeric chains: 1, photochlorinated polyethylene samples from a branched parent-polymer (LDPE); 2 , thermal-chlorinated polyethylene samples from a branched parent-polymer (LDPE).

relative proportion between the $T$ and $G$ conformations.

A plot of $A_{615} / A_{660 \rightarrow 685}$ against chlorine contents in weight (Figure 12) for the photochlorinated and thermal chlorinated CPE samples leads to the following conclusions:

$\mathrm{S}_{\mathrm{HC}}$ resonance mode prevail from the beginning of the chlorination reaction, i.e., $\mathrm{PVC}$ isotactic sequences are more numerous in the CPE chains than syndiotactic ones. From the 55-60-\% chlorine content interval up to $73 \%$, in the photochlorination process, $-\mathrm{CHCl}-\mathrm{CHCl}-$ $\mathrm{CH}_{2}-$ or $-\mathrm{CHCl}-\mathrm{CHCl}-\mathrm{CHCl}-$ and $-\mathrm{CHCl}-\mathrm{CH}_{2}-\mathrm{CCl}_{2}-$ structures arise from the chlorination of the isotactic portions of the PVC heterotactic tetrads and $G G$ portions of PVC syndiotactic sequences $T T G G .{ }^{13}$ As can be seen in Figure 12, the appearance of these new structures enhanced the $G$-conformation proportion in the CPE chains. From the 55-60-\% chlorine content interval up to the $73-\%$ level one must 
Chlorinated Polyethylene. I.

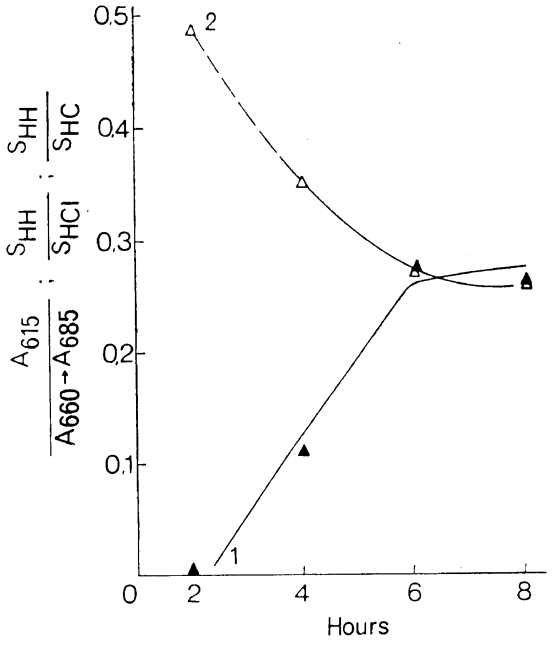

Figure 13. Conformational changes in the polymeric chains of polyethylene samples chlorinated beyond the minimum chlorination time necessary to obtain the saturation level $\left(73-\% \mathrm{Cl}_{2}\right): \triangle$, HDPE (linear polyethylene); $\Delta$, LDPE (branched polyethylene).

speak of $\mathrm{S}_{\mathrm{HC}}$ and $\mathrm{S}_{\mathrm{HCl}}$ resonance modes for the $685-\mathrm{cm}^{-1}$ band.

When the scheduled chlorination time necessary to reach the maximum chlorine content by weight is overrun ${ }^{4}$ the amount of $T$-conformation begin to increase again in the chains of the $73-\%$ CPE samples issued from a branched polyethylene. This evolution is related to an important mechanism $^{13}$ (Figure 13).

\section{Quantitative Structural Analysis}

Crowo and Fredriksen ${ }^{17}$ published an original method for calculating the ratio of number of $\mathrm{CH}_{2}$ units/number of $\mathrm{CHCl}$ units $\left(\mathrm{nb} \mathrm{CH}_{2} / \mathrm{nb}\right.$ $\mathrm{CHCl}$ ) for CPVC samples. They used the absorbance of the $\mathrm{CH}_{2}$ bending mode at $1428 \mathrm{~cm}^{-1}$ and the $\mathrm{CH}$-deformation mode at $1195 \mathrm{~cm}^{-1}$. For a PVC sample the ratio of these absorbances $\left(A_{1428} / A_{1195}\right)$ gives a number $\langle X X\rangle$ which is related to a $\mathrm{nb} \mathrm{CH}_{2} / \mathrm{nb} \mathrm{CHCl}=1$. Thus the calculated $A_{1428} / A_{1195}$ of a CPVC sample permits one to evaluate its ratio, $\mathrm{nb} \mathrm{CH}_{2} / \mathrm{nb} \mathrm{CHCl}$. But as the ratio, $A_{1428} / A_{1195}$, of a $\mathrm{PVC}$ is dependent on its tacticity $^{23)}$ this method is adequate only if the reference PVC sample is the parent-polymer of the analysed CPVC samples and under the assumption that tacticity does not rule the chlorination mechanism. Nevertheless, one can use it for routing calculation; for precise investigation the method based on NMR analysis is more accurate. $^{4-6,13}$

\section{CONCLUSION}

In connection with NMR investigations published elsewhere ${ }^{4-6}$ new bands have been identified in the CPE infrared spectrum. At the highest chlorine content by weight (73\%), CPE and CPVC have nearly the same spectrum, which is different from the PVDC one. Although NMR proves that $-\mathrm{CCl}_{2}-$ units are present in $\mathrm{CPE}$ chains, it is impossible to identify their $\mathrm{C}-\mathrm{Cl}$ stretching frequency.

In the case of overrunning the minimum scheduled chlorination time to reach the 73-\% chlorine level, one cannot use the $A_{1428} / A_{1434}$ ratio to calculate the syndiotacticity-index ${ }^{13}$ of the CPE because it is imposible to identify the 1434- $\mathrm{cm}^{-1}$ band.

Infrared analysis is an important tool for showing the influence of tacticity on the polyethylene chlorination mechanism. In another paper ${ }^{13}$ we will discuss the photochlorination and thermal chlorination mechanisms of lowdensity polyethylene and high-density polyethylene samples in connection with this infrared analysis.

\section{REFERENCES}

1. H. W. Thompson and P. Torkington, Trans. Faraday Soc., 41, 254 (1945).

2. K. Nambu, J. Appl. Polym. Sci., 4, 69 (1960).

3. T. Saito, Y. Matsumura, and S. Hayashi, Eur. Polym. J., 6, 639 (1970).

4. B. M. Quenum, P. Berticat, and Q. T. Pham, ibid., 7, 1527 (1971).

5. B. M. Quenum, P. Berticat, and Q. T. Pham, ibid.. 9, 777 (1973).

6. G. Humbert, B. M. Quenum, Q. T. Pham, P. Berticat, and G. Vallet, Macromol. Chem., 175, 1597 (1974).

7. B. M. Quenum, J. L. Grandaud, P. Berticat, and G. Vallet, Chim. Anal. (Paris), 53, 629 (1971).

8. B. M. Quenum, P. Berticat, and G. Vallet, Polymer J., 7, 300 (1975).

9. S. Mizushima, T. Shimanouchi, K. Nakamura, M. Hayashi, and S. Tsuchiya, J. Chem. Phys., 26, 970 (1957). 
10. S. Krimm, A. R. Berens, V. R. Folt, and J. J. Shipmann, Chem. Ind. (London), 433 (1959).

11. J. J. Shipman, V. R. Folt, and S. Krimm, Spectrochim. Acta, 18, 1603 (1962).

12. S. Krimm, V. L. Folt, J. J. Shipman, and A. R. Berens, J. Polym. Sci., Part A-1, 2621 (1963).

13. B. M. Quenum, P. Berticat, and G. Vallet, Polymer J., 7, 287 (1975).

14. S. A. Adilov, I. F. Leshcheva, D. E. Il'ina, M. V. Shishrina, and B. A. Krentjel, Neftekhimiya (3) 1, 82 (1963).

15. S. Krimm and C. Y. Liang, J. Polym. Sci., 22 95, (1956).

16. J. J. Fox and A. E. Martin, Proc. Roy. Soc. Ser. A, 175, 208 (1940).
17. V. O. Fredriksen and J. A. Crowo, Makromol. Chem., 100, 231 (1967).

18. N. Murayama and Y. Amagi, Polym. Letters, 4, 119 (1966).

19. S. Enomoto and S. Satoh, Kolloid-Z. Z. Polym., 219, 12 (1967).

20. G. Humbert, B. M. Quenum, P. Berticat, and G. Vallet, Makromol. Chem. 175, 1611 (1974).

21. W. G. Oakes and D. B. Robinson, J. Polym. Sci., 14, 505 (1954).

22. T. Shimanouchi and M. Tasumi, Spectrochim. Acta, 17, 755, (1961).

23. B. M. Quenum, P. Berticat, J. L. de la Pena, and J. Millan, Eur. Polym. J., 10, 157 (1974). 